\title{
Superior vena kava obstrüksiyonu olan iki hastada geçici hepatik kontrastlanma farklıı̆ı̆ı: Bilgisayarlı tomografi bulguları
}

\author{
Transient hepatic attenuation differences in two patients with superior vena cava obstruction: \\ Computed tomography findings
}

Ozdil BASKAN, Yusuf SAHINGOZ

\section{ÖZET}

Karaciğerin kanlanmasındaki hemodinamiklerin bozulması sonucunda tümöral süreç ile karışan parankimal geçici kontrastlanma farklılıkları oluşabilir. Etiyolojide tümöral veya tümöral olmayan süreçler rol oynar. Superior vena kava obstrüksiyonları, geçici hepatik kontrastlanma farklılığı (GHKF) etiyolojileri arasında son derece nadir olarak karşımıza çıkar.

Çalışmamızda, superior vena kava obstrüksiyonuna bağlı oluşan GHKF'nın bilgisayarlı tomografi bulguları sunulmuş ve tartışılmıştır.

Anahtar kelimeler: Superior vena kava obstrüksiyonu, Karaciğer, Bilgisayarlı tomografi

\begin{abstract}
Radiographic appearances of transient hepatic attenuation differences (THAD) can mimic tumors. THAD can occur as a result of altered hemodynamics of the hepatic blood flow. Tumoral or non-tumoral processes can play role in the etiology. THADs that appear secondary to the obstruction of the superior vena cava are rarely seen.

Herein, we present computed tomography findings of two cases with THAD secondary to superior vena cava obstruction.
\end{abstract}

Keywords: Superior vena cava, Liver, Computed tomography

Ozdil Baskan (四)

Radyoloji Anabilim Dall, Tip Fakültesi, Medipol Üniversitesi, İstanbul, Türkiye

e-mail: ozdil.baskan@yahoo.com

Yusuf Sahingoz

Radyoloji, Acıbadem Atakent Hastanesi, İstanbul, Türkiye

Gönderilme/Submitted: 07.11.2014

Kabul/Accepted: 13.12 .2014

\section{Giriş}

Malign ya da benign nedenlere bağlı santral ven oklüzyonlarında, üst ekstremite veninden verilen kontrast maddenin çeşitli torasik kollateraller aracılığıyla inferior vena kavaya doğru yönlenmesi sonucunda kontrastlı bilgisayarlı tomografi (BT) incelemesi sırasında karaciğerde tümöral lezyonlarla karışabilen geçici kontrastlanma farklılığ görülebilir. Superior vena kava (SVK) obstrüksiyonları, GHKF etiyolojileri arasında nadir olarak karşımıza çıkar [1].

Çalışmamızda iki olguda SVK obstrüksiyonuna bağlı oluşan geçici hepatik kontrastlanma farklılığı (GHKF)'nın BT bulguları sunulmuştur.

\section{Olgu Sunumu \\ Olgu 1}

Akciğer küçük hücreli tümörü nedeniyle takip edilen 67 yaşındaki erkek hastaya uygulanan tedavi sonrası kontrol amaçlı kontrastlı toraks ve abdomen BT incelemeleri yapıldı. Kontrol incelemeler sirasında herhangi bir yakınması mevcut değildi. Fizik muayene bulgularında özellik saptanmadı. İncelemeler 256-kesitli BT cihazıyla (Brilliancei CT, Phillips Healthcare), sol antekübital yoldan 70cc non iyonik kontrast madde (Iomeron 350, Bracco, Milan, Italy) $5 \mathrm{ml} / \mathrm{sn}$ hızla verilerek yapıldı. Karaciğer sol lob medial segmentte arteriyel fazda düzgün sınırlı kama şeklinde, intrahepatik vasküler yapılarda distorsiyona neden olmayan yoğun kontrast tutulumu izlendi (Şekil 1A). Portal ve hepatik venöz fazda bu alan izodansite ile karakterizeydi (Şekil 1B). Toraks BT incelemesinde arkus aorta düzeyinde antero posteriordan superior vena kavayı çevreleyen ve ileri derecede daraltan kitle lezyonu saptandı (Şekil 1C). İnferior vena kavada ince kalibrede kontrast madde izlendi. Hastada kontrast maddenin internal torasik ven, superior epigastrik ven ve Sappey veni ile karaciğere ulaştı̆̆ 1 saptandı. Karaciğerde izlenen yoğun 
arteryel kontrast tutan alan ve sonrasinda hepatik venler aracılığı ile vena kava inferiora doğru yönlenmiş olduğu izlendi. Perikardiofrenik ve diafragmatik venöz pleksuslar aracılığıyla da hepatik kontrast maddenin inferior kavaya ulaştığı izlendi (Şekil 1 D-F).

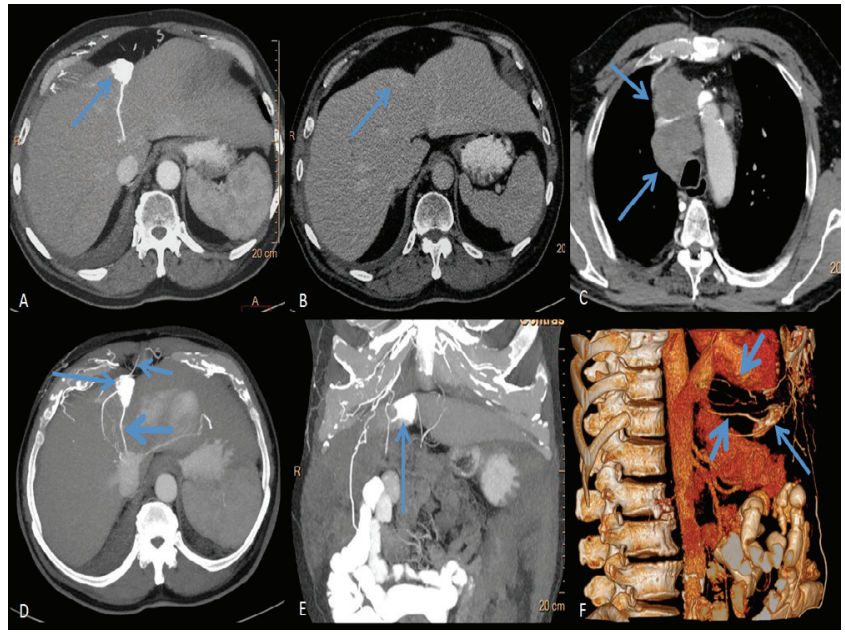

Şekil 1. (A) Karaciğer sol lob medial segmentte arteriyel faz görüntülerde düzgün sınırlı, kama şeklinde intrahepatik vasküler yapılarda distorsiyona neden yoğun olmayan kontrast tutulumu izleniyor (ok). (B) Aynı düzlemden geçen kesitlerde hepatik venöz fazda arteryel dönemde yoğun contrast tutan alan izodens olarak izleniyor (ok). (C) Superior vena kavada belirgin basiya neden olan lezyon oklüzyonu izlenmekte (ok). (D) Karaciğer sol lob medial segmentte arteriyel faz transvers, (E) Koronal MIP ve (F) Sagittal "volüm-rendering" görüntülerde yoğun kontrast tutulumu izlenen alan (uzun ok)

Sappey veni (D, k1sa ok) ve kontrast maddenin torasik kollateraller ( $\mathrm{F}$, kısa ok) aracılığıyla perikardiyofrenik ve hepatik venlerden vena kava inferiora doğru yönlenmiş olduğu izleniyor (F, kalın oklar).

\section{Olgu 2}

Midenin taşlı yüzük hücreli karsinomu tanısı bulunan, 58 yaşında kadın hastanın total gastrektomi öyküsü mevcuttu. Preoperatif dönemde yapılan toraks ve batın BT incelemelerinde patolojik bulgu saptanmadi. Hastaya adjuvan kemoterapi uyguland. Yüzünde şişme olması nedeniyle hastaya bölümümüzde 256-kesitli BT cihazıyla (Brilliancei CT, Phillips, Healthcare) sol antekübital yoldan 65cc non iyonik kontrast madde (Iomeron 350, Bracco, Milan, Italy) $5 \mathrm{ml} / \mathrm{sn}$ hizla verilerek yapıldı. Sol subklavian vende, brakiosefalik vende ve superior vena kava proksimalinde lümene kontrast maddenin geçişi izlenmedi. Yukarıda belirtilen vasküler yapıların lümeninde hipodansite ile karakterize trombüs mevcuttu (Şekil 2 A). Gögüs duvarı sol lateral kesimde, solda supraklaviküler alanda ve sirtta skapula komşuluğunda ve karın ön duvarında sol paramedian kesimde cilt-cilt altı yağ dokusunda, kas yapıları içerisinde multipl sayıda kollaterallere ait görünümler mevcuttu (Şekil 2 A-D). Kontrast maddenin yüzeyel lateral torasik venler ve internal torasik venler aracılığı ile diafragmatik venöz pleksuslara ulaştığı izlendi. Mediastende yaygın venöz kollateral ağlar gözlendi. Multipl perikardial venler, büyük damarlar boyunca intraperikardiyal küçük vasküler yapılarla devamlılık gösteriyorlardı. Perikardiofrenik ve kardiofrenik venler ile subdiafragmatik alanda vena kava inferiora ulaşıyordu (Şekil 2 C). Karaciğer sol lob medial segmentte arteriyel fazda düzgün sınırlı, kama şeklinde, yoğun kontrast tutulumu gösteren alan izlendi (Şekil 2 D). Kontrast madde hepatik venlere sonrasında ise inferior vena kavaya yönlenmekteydi. Portal ve hepatik venöz fazda bu alan izodansite ile karakterizeydi.

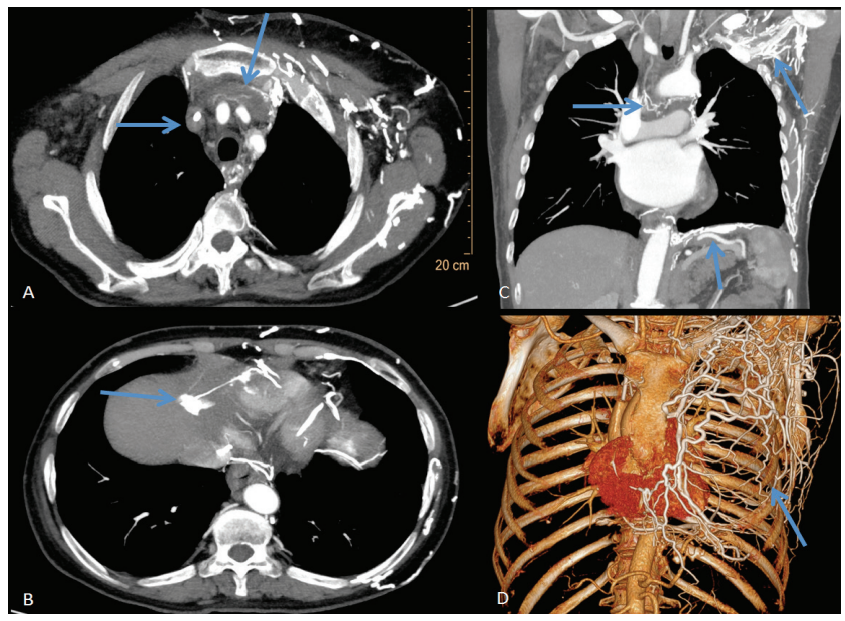

Şekil 2. (A,oklar) Sol brakiosefalik ven ve superior vena kava proksimalinde lümende kontrast madde izlenmiyor. (B,oklar) Göğüs duvarı sol lateral kesimde, solda supraklaviküler alanda ve skapula komşuluğunda ve karın ön duvarında sol paramedian kesimde multipl sayıda kollateraller görülmekte. Kontrast maddenin yüzeyel lateral torasik venler ve internal torasik venler aracılığı ile diafragmatik venöz pleksuslara ulaşıyor. (C,oklar) Mediastende yaygın venöz kollateral ağlar, multipl perikardial venler büyük damarlar boyunca intraperikardiyal küçük vasküler yapılar. (D,oklar) Karaciğer sol lob medial segmentte arteriyel fazda düzgün sınırlı, kama şeklinde, yoğun kontrast tutulumu gösteren alan.

\section{Tartışma}

Karaciğerde $\% 25$ hepatik arterden, $\% 75$ portal venden gelen kan akımı vardır [2]. Karaciğerin büyük kısmı bu dual kan akımı ile beslenirken subkapsüller bazı alanlar başka bir venöz sistem (kolesistik, parabilier veya epigastrik-paraumbilikal) 
ile beslenir [3-5]. GHKF, karaciğerin hepatik arteryel, portal venöz ve hepatik kan akımının üçüncü giriş kaynaklarının arasındaki dengenin bölgesel farklılıklarının oluşturduğu görüntüleme bulgusudur. Etkilenen alanda dinamik kontrastl1 BT incelemesinde, hepatik arteryel fazda yoğun kontrast tutulumu portal ve venöz fazlarda normal parankim ile izodens hale dönüş söz konusudur. GHKF tipik olarak kama şeklinde izlenir. GHKF etiyolojisinde, arterioportal şant, vasküler kompresyon, inflamasyon, vasküler varyasyon, hepatik parankimal kompresyon ve hipervasküler tümörlerde çalma sendromu gibi nedenler yer alır $[1,6,7]$.

SVK obstrüksiyonu, GHKF etiyolojileri arasında nadir olarak karşımıza çıkar [8,9]. SVK obstrüksiyonu çeşitli nedenlere bağlı olarak gelişebilir. En sık nedeni malignensiler olup, vaskülitler, mediastinal fibrozis, radyasyon, thrombozis gibi benign süreçlere de sekonder olarak görülebilir. SVK obstrüksiyonunda karaciğer sol lobu medial segmentinde GHKF görülebilmektedir [10]. SVK obstrüksiyonlarında üst ekstremiteden gelen kan birçok ana ve aksesuar kollateral yollara dağılmaktadır. Bunlardan bazıları azigos-hemiazigos venler, internal mamarian ven, vertebral venöz pleksus yol, lateral torasik ve yüzeyel torakoabdominal venlerdir. Üst ekstremiteden verilen kontrast madde karaciğere sıklıkla internal torasik ven, superior epigastrik ven ve superior Sappey ven ile direkt ulaşır. Karaciğer IV. segment superiorunda arteryel fazda yoğun kontrast tutulumuna neden olur [11]. Bizim ilk sunduğumuz hasta akciğerin küçük hücreli tümörü nedeniyle takip edilmekteydi. Mediastinal yerleşimli primer malign kitlenin bası ve invazyonuna bağlı olarak gelişen SVK obstrüksiyonu gelişmişti. SVK obstrüksiyonu nedeniyle kontrast madde internal torasik ven, superior epigastrik ven ve Sappey veni ile karaciğere ulaşmakta olup karaciğer sol lob medial segmentinde arteriyel fazda düzgün sınırl1, intrahepatik vasküler yapılarda distorsiyona neden olmayan yoğun kontrast tutulumuna neden olmaktaydı (Şekil 1). Hepatik venler aracılığı ile vena kava inferiora doğru yönlenmişti. İkinci sunduğumuz hastamızda ise tıkanıklığa etiyolojide brakiosefalik ven ve SVK trombüsü rol oynamakta olup sol aynı taraf göğüs duvarında, mediastende, perikardial alanda ve subdiyafragmatik bölgede fazla miktarda kollateral mevcuttu. Karaciğer sol lob medial segmentte birinci olgu ile benzer tarzda arteryel fazda düzgün sınırlı, intrahepatik vasküler yapılarda distorsiyona neden olmayan yoğun kontrast tutulumu izlendi (Şekil 2). Bu görünüm portal ve venöz fazlarda parankim ile izodens hale gelmekteydi.

GHKF, yanlış tedavi ve gereksiz girişimlerin engellenmesi için vasküler malformasyonlar, primer karaciğer malign tümörleri, hipervasküler metastazlar, hemanjiom, fokal nodüler hiperplazi, adenoma gibi özellikle erken arteryel dönemde kontrast tutulumu gösteren lezyonlardan ayırt edilmelidir. Karaciğer parankiminde kontrast tutan alanın kama şeklinde ve düzgün sınırlı olması, vasküler yapılarda itilmeye yol açmaması, çevre parankimde bası etkisi oluşturmaması gibi özellikleri GHKF tanısında yol gösterir. Kontrastlı çalışmalarda arteriyel fazda yoğun kontrast tutan alanlar olarak izlenirken, portal ve hepatik venöz fazlarda normal parankim ile izodens hale gelirler. Bu özellikleri ile karaciğer tümörlerinden ve diğer karaciğer patolojilerinden ayırımı mümkündür. Ayrıca etiyolojisi SVK obstrüksiyonu olan olgularda kontrast madde ile dolu venöz kollaterallerin görülmesi ayırıcı tanıda yardımcıdır.

\section{Kaynaklar}

1. Quiroga S, Sebastià C, Pallisa E, et al. Improved diagnosis of hepatic perfusion disorders: value of hepatic arterial phase imaging during helical CT. Radiographics 2001;21:65-8. doi: http://dx.doi.org/10.1148/radiographics.21.1.g01ja0165

2. Itai Y, Matsui O. "Nonportal" splanchnic venous supply to the liver: abnormal findings on CT, US, and MRI. Eur Radiol 1999;9:237-43. doi:10.1007/s003300050661

3. Matsui O, Takahashi S, Kadoya M, et al. Pseudolesion in segment IV of the liver at CT during arterial portography: correlation with aberrant gastric venous drainage. Radiology 1994;193:31-5. doi: http://dx.doi.org/10.1148/ radiology.193.1.8090916

4. Yoshimitsu K, Honda H, Kaneko K, et al. Anatomy and clinical importance of cholecystic venous drainage: helical CT observations during injection of contrast medium into the cholecystic artery. AJR Am J Roentgenol 1997;169:505-10. doi: 10.2214/ajr.169.2.9242765

5. Desser TS. Understanding transient hepatic attenuation differences. Semin Ultrasound CT MR. 2009;30(5):408-17. doi:10.1053/j.sult.2009.07.003.

6. Colagrande S, Centi N, Galdiero R, Ragozzino A. Transient hepatic intensity differences: part 1, Those associated with focal lesions. AJR Am J Roentgenol 2007;188:154-9. doi:10.2214/AJR.05.1368

7. Colagrande S, Centi N, Galdiero R, Ragozzino A. Transient hepatic intensity differences: part 2, Those not associated with focal lesions. AJR Am J Roentgenol 2007;188:160-6. doi: 10.2214/AJR.05.1367

8. Baba Y, Miyazono N, Inoue H, et al. Altered flow dynamics of intravascular contrast material to the liver in superior vena cava syndrome: CT findings. Abdom Imaging 2000;25:14650. doi: 10.1007/s002619910034

9. Bashist B, Parisi A, Frager DH, Suster B. Abdominal CT findings when the superior vena cava, brachiocephalic vein, or subclavian vein is obstructed. AJR Am J Roentgenol 1996;167:1457-63. doi: 10.2214/ajr.167.6.8956577 
10. Maldjian PD, Obolevich AT, Cho KC. Focal enhancement of the liver on CT: a sign of SVC obstruction. J Comput Assist Tomogr 1995;19:316-8. doi: 10.1097/00004728-19950300000029
11. Dahan H, Arrive L, Monnier-Cholley L, Le Hir P, Zins M, Tubiana JM. Cavoportal collateral pathway in vena cava obstruction: imaging features. AJR Am J Roentgenol 1998;171:1405-11. doi: 10.2214/ajr.171.5.9798887 